\title{
ESCALA DE AVALIAÇÃO DE DEPRESSÃO PARA CRIANÇAS: UM ESTUDO DE VALIDAÇÃO*
}

\author{
CHILDREN DEPRESSION EVALUATION SCALE: \\ A VALIDITY ASSESSMENT
}

\author{
Dejenane Aparecida Pascoal PEREIRA ${ }^{1}$ \\ Dra. Vera Lúcia Adami Raposo do AMARAL ${ }^{2}$
}

\begin{abstract}
RESUMO
A presente pesquisa teve por objetivo realizar um estudo de validação da "Escala de Avaliação de Depressão para Crianças" de Amaral e Barbosa (1990). Durante a realização da pesquisa a escala inicial foi modificada, obtendo-se quatro versões. Foi realizada análise semântica dos itens junto a duas amostras de crianças $(N=12$ e $N=4)$. A seguir, quatro psicólogos clínicos e três psiquiatras analisaram a pertinência dos itens ao construto. $E$, finalmente, a escala foi aplicada à amostra de 362 estudantes, de escolas públicas e particulares, para o estudo da precisão e da validade de construto. Utilizou-se a análise fatorial exploratória; os índices de poder discriminativo dos itens, desvio-padrão e correlação corrigida item-total de Pearson; e o cálculo do Coeficiente Alfa $(\alpha)$, de Cronbach. Na compreensão semântica dos itens um item foi excluído e três foram reformulados. Não houve itens descartados na análise de juízes. Na análise fatorial exploratória observouse que as quatro primeiras dimensões explicam $33,36 \%$ da variabilidade total dos dados, com autovalores acima de 1,4. Quatro itens foram descartados por apresentarem carga-fatorial menores do que 0,40. Na análise do poder discriminativo dos itens eliminaram-se seis itens com correlação item-total próximas de zero. A escala final ficou composta de 24 itens distribuídos segundo quatro fatores: resposta afeto-disfórico $(\alpha=0,70)$; resposta afetivo-emocional com conteúdo de ansiedade $(\alpha=0,65)$; resposta fisiológico-autonômica $(\alpha=0,56)$; e resposta cognitiva com conteúdo de auto-estima $(\alpha=0,50)$.
\end{abstract}

Palavras-chave: Depressão infantil, avaliação psicológica, instrumentos e medidas.

\footnotetext{
(*) Este texto é parte integrante da Dissertação de Mestrado de Dejenane Aparecida Pascoal Pereira realizada sob orientação de Vera Lúcia Adami Raposo do Amaral, defendida em setembro de 2002, na Faculdade de Psicologia do Centro de Ciência da Vida da PUC-Campinas.

(1) Mestre em Psicologia Escolar e Doutoranda em Psicologia pela PUC-Campinas, Docente da Universidade de Taubaté. Endereço para correspondência: Rua: Vereador Roberto Gelsomini, 154 - Barra Funda Guarujá/SP - Cep: 11410-400 E-mail: pereiradap@uol.com.br

(2) Professora Doutora em Psicologia no Programa de Pós-graduação em Psiologia da PUC-Campinas.
} 


\begin{abstract}
The aim of this survey is to perform a validity assessment of the "Children Depression Evaluation Scale" from Amaral and Barbosa (1990). Through the research, the initial scale has been modified, resulting in four versions. It has been carried out a semantic analysis of the items with two samples of children ( $N=12$ and $N=4)$. Subsequently, four Clinical Psychologists and three Psychiatrists analyzed the pertinence of the items to the construct. Finally, the scale was applied to the 362 students from public and private schools, for the study of the precision and the validity of the construct. It was used the exploratory factorial analysis; the discriminative power index of the items, standard-deviation and Pearson's item-total corrected correlation; and the Cronbach's Alfa Coefficient calculation $(\alpha)$. In the semantic comprehension of the items, one item has been excluded and three items reformulated. There has been no disregard items in the judges analysis. In the exploratory factorial analysis it has been observed that the first four dimensions explained $33,36 \%$ of the total variability of the data, with self values over 1.4. Four items were discarded due to presenting factorial-load under 0.4. In the discriminative power analysis of the items, six items were eliminated with total-item correlation close to zero. The final scale comprised 24 items distributed according to four factors: disforical affection response $(\alpha=0,70)$; emotional-affective response with anxiety contort $(\alpha=0,65)$; autonomous-physiological response $(\alpha=0,56)$, and cognitive response with self-esteem content $(\alpha=0,50)$.
\end{abstract}

Key words: Child depression, psychological assessment, instruments, mesurement.

\section{INTRODUÇÃO}

Os instrumentos psicológicos psicométricos são recursos científicos utilizados pelos profissionais psicólogos em diversas áreas da Psicologia como meio de auxílio em avaliações psicológicas, pesquisas científicas e mesmo no acompanhamento de tratamentos. A necessidade e a importância das medidas padronizadas são citadas na literatura nacional e internacional (Pereira, 2002). A principal razão para uso dos testes é descrever comportamentos ou outras qualidades importantes com precisão (Oakland, 1999).

Conforme Anastasi e Urbina (2000), “... a pergunta mais importante a ser formulada sobre qualquer teste psicológico refere-se à validade, isto é, o grau em que o teste realmente mede aquilo que se propõe a medir" (p. 22). Para garantir a validade de um teste psicológico, é necessário que ele seja avaliado por meio de múltiplos procedimentos. Os testes utilizados para decisões importantes e que apresentam influência significativa na vida do sujeito freqüentemente são padronizados e mais cuidadosamente desenvolvidos (Oakland, 1999).

O ramo da Psicologia responsável pela construção e validação dos testes psicológicos é a Psicometria. Os testes psicológicos, os inventários, as escalas e outros estão incluídos na medida escalar, uma das formas de medida psicométrica bastante utilizada para medir traços de personalidade. Os fundamentos principais das medidas escalares são os parâmetros de medida (validade e fidedignidade). O conceito de 
escala psicométrica é, geralmente, utilizado quando se visa escalonar estímulos que expressam um construto psicológico, como uma técnica de se fazer medida (Pasquali, 1996).

Na literatura científica há diversas escalas com o objetivo de avaliar a depressão, auxiliando na elaboração do diagnóstico juntamente com outros dados clínicos, cumprindo a função de detectar o grau de gravidade dos sintomas e acompanhando o resultado de tratamentos (Calil \& Pires, 2000; Moreno \& Moreno, 2000). Na literatura nacional há carência e necessidade de escalas para depressão infantil que sejam válidas para crianças brasileiras, e que avaliem a depressão em nosso contexto cultural (Pereira, 2002).

Em 1980, o distúrbio de humor em crianças foi incluído na categoria diagnóstica de doença psiquiátrica. Pode-se afirmar que os estudos referentes à depressão em crianças ainda se encontram em fase de desenvolvimento (Brown, 2000).

Este estudo teve como objetivo validar uma escala de depressão para crianças, partindo de um instrumento inicialmente elaborado por Amaral e Barbosa (1990) com a finalidade de estudar depressão em crianças queimadas.

\section{Diagnóstico da Depressão Infantil}

As desordens depressivas em crianças e adolescentes são associadas freqüentemente a prejuízo do comportamento psicossocial e baixa do rendimento escolar. O diagnóstico da depressão infantil ainda é difícil de ser realizado, devido às suas variáveis funcionais e à justaposição que apresenta com outras psicopatologias da infância. As dificuldades em torno do diagnóstico da depressão também são presentes no caso de adultos e adolescentes. Isto também se deve a diversas classes de depressão existentes. Sistemas diagnósticos como o DSM-IV (Manual Diagnóstico e Estatístico de Transtornos Mentais) e a CID-10 (Classificação de Transtornos Mentais e de Comportamento) têm sido desenvolvidos com o intuito de diminuir a variabilidade na interpretação dos sintomas
(Birmaher, Ryan, Williamson, Brent \& Kaufman, 1996).

O DSM-IV e a CID-10 são os manuais diagnósticos usualmente citados na literatura científica, além de serem os mais aceitos. Porém, há clínicos que utilizam outras formas de diagnóstico da depressão: depressão exógena versus depressão endógena; depressão neurótica versus psicótica; depressão agitada versus retardada; depressão dupla e afetividade negativa (Miller, 1998).

O DSM-IV apresenta quatro tipos de depressão na seção de transtornos do humor: depressão maior, distimia, ciclotimia e desordem bipolar. Estes tipos de depressão são diagnosticados com base nos episódios apresentados pelo indivíduo, por exemplo: para o diagnóstico de depressão maior, o indivíduo deve apresentar um ou mais episódios depressivos. Os episódios são categorias que descrevem sintomas específicos. O DSM-IV lista quatro categorias de episódios do humor: episódio depressivo maior, episódio maníaco, episódio misto e episódio hipomaníaco.

$\mathrm{Na}$ CID-10, os tipos de depressão listados sobre o bloco transtornos do humor (afetivos) são: transtorno afetivo bipolar; transtorno depressivo recorrente; e transtornos persistentes do humor (afetivos). Este bloco não apresenta diferenciações entre crianças, adolescentes e adultos. Nele se insere o episódio maníaco e o episódio depressivo.

Para Miller (1998), a depressão infantil é uma desordem cíclica com períodos intercalados de depressão e de bem-estar. Este autor, com base no diagnóstico da depressão no DSM-IV, enfoca dois tipos de episódios que uma criança ou adolescente com transtorno de humor pode experimentar: o episódio depressivo e o episódio maníaco. Em seguida, descreve os sintomas típicos da depressão infantil, citando quatro classes principais de distúrbios experimentados por crianças e adolescentes: 1) pensamento; 2) emoções; 3) comportamento e 4) processo fisiológico. 
Nos sintomas do episódio depressivo, o autor destaca o caráter subjetivo e fenomenológico do pensamento. As crianças deprimidas pensam a partir de sua própria perspectiva. Esta condição relaciona-se a problemas de baixa auto-estima, culpa, vergonha e autocrítica, e podem ocorrer relatos de que são más e não merecem ser felizes. Outras condições verificadas são: dificuldade de concentração e de pensamento, pensamentos de morte e suicídio (pensar em querer morrer ou como se matariam). Em termos de sentimento, destacam-se o humor deprimido quase todos os dias e o interesse diminuído por atividades prazerosas. Já em relação aos problemas comportamentais destaca-se a agitação ou o retardo psicomotor. Em termos fisiológicos, ocorre perda significativa ou ganho de peso, ou seja, quando há apetite diminuído ou aumentado. Para crianças mais jovens ocorrem falha em alcançar o peso esperado no processo de desenvolvimento, insônia ou hipersonia quase todos os dias, fadiga e falta de energia - a criança reclama que está cansada, não se sente motivada - ou, ainda, tem dores físicas e desconforto.

Ainda de acordo com Miller, nos sintomas do episódio maníaco, a criança apresenta pensamento rápido ou fica incapaz de completálo; em casos mais graves há uma continuidade de conversa com mudança rápida de assunto. Já na distrabilidade, também incluída em sintomas de pensamento, a criança terá dificuldade para fixar sua atenção. Também no episódio maníaco, nos problemas com sentimento, as crianças apresentam auto-estima inflada ou idéias de grandiosidade, podendo ocorrer sentimentos de serem invencíveis ou suscetíveis no exagero de suas habilidades. Nos problemas relacionados ao comportamento do episódio maníaco, a criança exibe dificuldades para ficar quieta, age como se houvesse pressão para se manter falando; outros sintomas que podem ser percebidos são maior atividade para alcançar uma meta; este sintoma pode manifestar-se por uma agitação psicomotora, e o envolvimento excessivo numa tarefa, por exemplo: a criança gasta todo seu dinheiro com bobagens. Alguns problemas fisiológicos também ocorrem no episódio maníaco e incluem reduzida necessidade de dormir; assim, a criança diz que está descansada após poucas horas de sono.

No DSM-IV, o episódio depressivo maior, incluído em todos os tipos de depressão, caracteriza-se por um humor deprimido ou pela perda de interesse ou prazer em quase todas as atividades na maior parte do dia, por um período mínimo de duas semanas, além de causar prejuízo no funcionamento social, profissional ou em outras áreas relevantes na vida do indivíduo. Além disso, a pessoa deve apresentar quatro sintomas adicionais: "alterações no apetite ou peso, sono e atividade psicomotora; diminuição da energia, sentimentos de desvalia ou culpa; dificuldade para pensar, concentrar-se ou tomar decisões; e pensamentos recorrentes sobre morte ou ideação suicida, planos ou tentativas de suicídio" (Associação Americana de Psiquiatria, 2000 , p. 306). Em crianças e adolescentes o humor pode ser irritável e, no tocante às alterações no apetite ou peso, as crianças podem não ter um aumento de peso esperado em seu desenvolvimento. Em relação às dificuldades para pensar e concentrar-se, nota-se a queda do rendimento escolar. Desse modo, percebe-se que os sintomas básicos não são diferentes em crianças e adolescentes, embora as crianças usualmente apresentem queixas somáticas, irritabilidade e retraimento social. Já na pré-puberdade, o retardo psicomotor, a hipersônia e os delírios são menos comuns do que na adolescência e na idade adulta.

Diferentemente do DSM-IV, o episódio depressivo na CID-10 engloba três variedades: leve, moderado e grave. Entretanto, esta classificação deve ser utilizada para um episódio depressivo único. Os sintomas típicos apresentados são: humor deprimido, perda de interesse e de prazer e fatigabilidade aumentada e atividade diminuída, além de outros sintomas comuns: concentração e atenção reduzidas; auto-estima e auto confiança reduzidas; idéias de culpa e inutilidade; visões desoladas e pessimistas do futuro; idéias ou atos autolesivos ou suicídio; sono perturbado e apetite diminuído. 
A classificação do episódio depressivo depende de vários fatores, descritos a seguir: para o diagnóstico do episódio depressivo leve, os sintomas não devem ser intensos, e a duração mínima é de duas semanas, com pelo menos dois dos sintomas típicos presentes e mais, pelo menos, dois dos outros sintomas comuns; no episódio depressivo moderado, os sintomas devem apresentar-se com um grau marcante, e sua duração mínima também é de duas semanas, com pelo menos dois sintomas típicos e pelo menos três dos outros sintomas comuns presentes; para o episódio depressivo grave sem sintomas psicóticos devem estar presentes, por pelo menos duas semanas, os três sintomas típicos dos episódios depressivo leve e moderado, e mais quatro dos outros sintomas com uma intensidade grave; no episódio depressivo grave com sintomas psicóticos devem estar presentes delírios, alucinações ou estupor depressivo e mais os mesmos sintomas e critérios utilizados para o episódio anterior.

Outro episódio, descrito pelo DSM-IV, é o maníaco, e ocorre em indivíduos diagnosticados com transtorno de humor ciclotímico e transtorno de humor bipolar. Define-se pela duração de pelo menos duas semanas de humor anormal, persistentemente elevado, expansivo ou irritável, que deve ser acompanhado por pelo menos três sintomas adicionais, que incluem "... auto-estima inflada ou grandiosidade, necessidade de sono diminuída, pressão por falar, fuga de idéias, distrabilidade, maior envolvimento em atividades dirigidas a objetivos ou agitação psicomotora, e envolvimento excessivo em atividades prazerosas com um alto potencial para conseqüências dolorosas" (Associação Americana de Psiquiatria, 2000, p. 313). Já no caso de um humor irritável, pelo menos quatro dos sintomas descritos devem estar presentes; a irritabilidade costuma ser freqüente e pode mudar bruscamente para raiva ou depressão.

Entretanto, podem ocorrer sintomas maníacos e depressivos simultaneamente, os sintomas depressivos podem durar momentos, horas ou dias. Porém, se houver critério para o episódio depressivo maior e para o episódio maníaco todos os dias, por pelo menos uma semana, o diagnóstico é de episódio misto. Em adolescentes, os episódios maníacos são associados a faltas às escola, comportamento anti-social, repetência ou ao uso de substâncias, e à maior tendência a incluir características psicóticas.

O episódio maníaco, conforme a CID-10, é caracterizado essencialmente por humor elevado e aumento de quantidade e velocidade da atividade física e mental. Este episódio inclui três graus de gravidade: a hipomania, a mania sem sintomas psicóticos e a mania com sintomas psicóticos.

Sendo o episódio maníaco relacionado às desordens bipolares, é válido destacar que em crianças e adolescentes as desordens bipolares são freqüentemente mal diagnosticadas e confundidas com desordens de comportamento e esquizofrenia; a sintomatologia é sobreposta a outras desordens como, por exemplo, o transtorno de hiperatividade associado ao déficit de atenção; as variações do desenvolvimento estão presentes (Gill, Coffey \& Park, 2000; McClellan \& Werry, 1997; Notelmann \& Jensen, 1995). Geralmente, o diagnóstico em crianças e adolescentes é baseado no mesmo critério usado para os adultos no DSM-IV, pois os dados sugerem que a desordem bipolar antes da idade de 18 anos é, essencialmente, a mesma de adultos. Muitos estudos são ainda necessários para verificar o curso a longo prazo e os tipos apresentados em crianças, principalmente com idade abaixo de 13 anos (McClellan \& Werry, 1997). "Caracteristicamente, a mania em crianças apresenta um curso crônico com história de irritabilidade, acessos de raiva e labilidade emocional; ..." (Gill, Coffey \& Park, 2000, p. 113).

O transtorno ciclotímico, conforme o DSMIV, estáincluído na seção de transtornos bipolares, abrange numerosos períodos de sintomas hipomaníacos e numerosos períodos de sintomas depressivos, que não satisfazem o critério para o episódio depressivo maior e nem para o episódio maníaco. Em crianças deve ocorrer por um período de um ano, diferentemente para dos adultos, nos quais deve ocorrer por um período de dois anos. 
Na ciclotimia, descrita na CID-10, o humor instável é marcado por períodos de depressão e elação leve. Usualmente ocorre no início da vida adulta e não preenche os critérios para transtorno afetivo bipolar e para transtorno depressivo recorrente.

O transtorno distímico é outro tipo de depressão listado no DSM-IV; sua característica principal é "um humor cronicamente deprimido que ocorre na maior parte do dia, na maioria dos dias, por pelo menos 2 anos" (Associação Americana de Psiquiatria, 2000, p. 329). Para uma criança ser diagnosticada com distimia, deve experimentar humor deprimido ou irritabilidade por, pelo menos, um ano. A criança, como o adulto, deve, ainda, apresentar dois ou mais dos seguintes sintomas: "apetite diminuído ou hiperfagia, insônia ou hipersonia, baixa energia ou fadiga, baixa auto-estima, fraca concentração ou dificuldade em tomar decisões e sentimentos de desesperança" (Associação Americana de Psiquiatria, 2000, p. 329).

$\mathrm{Na}$ CID-10, a distimia refere-se à depressão crônica do humor. As pessoas sentem-se cansadas e deprimidas e, na maior parte do tempo, sintomas como preocupações, queixas, sono perturbado e sentimentos de inadequação estão presentes, mas as pessoas são capazes de lidar com as exigências do dia-a-dia.

A citação dos manuais CID-10 e DSM-IV visou apontar para uma descrição mais precisa do diagnóstico da depressão contidos nesses, visto que eles são referência na área da saúde mental, como já relatado anteriormente. Pode-se verificar que são poucas as diferenciações entre o diagnóstico da depressão em adultos e o diagnóstico da depressão infantil. Provavelmente pelo fato de a depressão infantil ter sido reconhecida recentemente, assim como o início ainda precoce de seus estudos.

Diversos fatores de dificuldades têm sido relatados na literatura científica para o diagnóstico da depressão infantil. Uma dessas dificuldades é que cada criança experimenta e manifesta a depressão de um modo variado. Além disso, geralmente as crianças não têm idéia ou não sabem que são depressivas. Devido à sua pouca experiência, podem não discriminar que o que estão sentindo ou manifestando não é normal. Outro fator de dificuldade é que a criança não pode ser avaliada em detrimento de características da sua personalidade. A personalidade da criança ainda está em desenvolvimento e em formação (Assumpção Jr., 2000). Outros fatores aos quais se atribuem esses problemas são: definição inadequada e critério diagnóstico; informação limitada sobre as variações de sintoma desenvolvimental entre crianças e adultos; falta de instrumentos de avaliação adequados; e relutância em reconhecer a seriedade da depressão infantil. Aliadas a estes fatores estão a comobirdade e a justaposição de sintomatologia entre a depressão e outras desordens de crianças (Mesquita \& Gilliam, 1994).

Alguns dos fatores de dificuldades no diagnóstico da depressão infantil ressaltam a necessidade de as pessoas que convivem com crianças, tais como pais e professores, estarem atentas a como elas funcionam. Informações obtidas em outras fontes indicam que, além dos pais, a própria criança e os professores são importantes, porque auxiliam no diagnóstico. As informações relatadas pelos pais são mais relativas às dificuldades de comportamento de seus filhos (Birmaher et al., 1996). Já Stark, Swearer, Delaune, Knox e Winter (1995) afirmam que os pais também podem relatar de modo preciso informações de tempo relacionado à depressão em seus filhos, tais como: início do episódio, quanto tempo passou, como os sintomas freqüentemente estão presentes na média semanal e quantos sintomas se passam no curso do dia.

Diferenças de como cada criança experimenta e manifesta a depressão devem ser consideradas para a realização do diagnóstico. Por exemplo: algumas crianças podem apresentar atitudes passivas, como retraimento e obediência; não incomodam os adultos e, conseqüentemente, não são tratadas. Já na adolescência a depressão pode ser vista de modo normal, ou seja, como parte do próprio processo de desenvolvimento desta faixa etária (Miller, 1998). Dificuldades 
para o diagnóstico da depressão em crianças levam a erros na precisão de diagnóstico e na identificação completa do problema (Mesquita \& Gilliam, 1994).

\section{Instrumentos de Medida da Depressão}

Como a criança é considerada uma fonte primária de informações sobre sua experiência subjetiva na depressão (Stark et al.,1995) e, no sentido de verificar se o tratamento é efetivo, os instrumentos de medida, com sólidas propriedades psicométricas da depressão infantil, são de grande valor e utilidade, pois possibilitam a avaliação da presença e severidade de sintomas da depressão que são experimentados pela criança. Além disso, permitem a análise de severidade dos sintomas no curso do tratamento e o auxílio aos profissionais na identificação precoce desta doença que é tão complexa.

O diagnóstico precoce faz com que os comportamentos depressivos possam ser tratados e/ou modificados mais facilmente e torna difícil a esses comportamentos criarem resistências a mudanças (Andriola \& Cavalcante, 1999).

As medidas de auto-relato para depressão, quando utilizadas em settings não clínicos, são um recurso para triagem, auxiliando os profissionais no rápido encaminhamento de crianças com possível depressão. Além disso, sua utilização em pesquisas científicas colabora para melhor compreensão do construto depressão em crianças.

As escalas de auto-avaliação são econômicas, pois requerem pouco tempo do profissional ou da equipe; suas desvantagens estão na dificuldade em avaliar sua fidedignidade, e sua utilização requer indivíduos com certo nível de educação, cooperantes e sem uma psicopatologia grave. As escalas diferenciam-se pelas categorias de sintomas que serão incluídos nos itens. (Calil \& Pires, 2000).

Na avaliação da depressão em crianças, o CDI (Inventário de Depressão Infantil), planejado por Maria Kovács e Beck, tem sido amplamente utilizado nos Estados Unidos (Smucker, Craighead, Craighead \& Green, 1986). O CDI é um inventário de auto-relato elaborado para crianças com idades entre sete e 17 anos, inclui 27 itens e tem como objetivo medir a presença e severidade de sintomas da depressão, avaliando suas diversas dimensões clinicamente relevantes: afetividade (por ex. humor rebaixado, solidão e irritabilidade); cognitiva (por ex. auto-imagem negativa, auto-culpa, expectativas negativas em decisão); motivacional (por ex. reclusão, evitamento, ideação suicida); vegetativo (por ex. distúrbio de apetite e de sono) e psicomotor (Hodges, Siegel, Mullins \& Griffin, 1983).

Outro instrumento para avaliar a sintomatologia depressiva em crianças é o RCDS (Escala de Depressão para Crianças de Reynolds), construído por Reynolds, da Universidade de Wisconsin - Madison, nos Estados Unidos (Reynolds, 1989). O RCDS consiste em uma medida de auto-relato com níveis clinicamente relevantes de sintomatologia depressiva, incluindo sintomas cognitivos, vegetativo-motores, somáticos e sintomas interpessoais.

Uma proposta para adaptar o CDI para o contexto brasileiro foi realizada por Gouveia, Barbosa, Almeida e Gaião (1995), em uma amostra de 305 crianças de escolas públicas e particulares, com idades variando entre oito e 15 anos, sendo a maioria do sexo masculino. Os autores relatam o instrumento como unidimensional com consistência interna aceitável e sugerem uma amostra maior, para elaboração de normas definitivas. Segundo a adaptação e normatização do CDI realizada por Gouveia, outros dois autores, Baptista e Golfeto (2000), verificaram a prevalência de depressão em escolares de sete a 14 anos na cidade de Ribeirão Preto.

Outro estudo com a população brasileira foi de Andriola e Cavalcante (1999), que avaliou a depressão em crianças da pré-escola utilizando a Escala de Sintomatologia Depressiva para Professores (ESDM-P), na cidade de Fortaleza (CE). A amostra foi de 345 crianças com idade média de 5,6 anos; a maioria eram meninas. Os 
resultados mostram prevalência de 3,9\% quanto ao indicativo de depressão das crianças.

Amaral e Barbosa (1990) desenvolveram um instrumento para avaliar a depressão infantil que foi testado em um estudo piloto e aplicado numa população de crianças vítimas de queimadura. A escala contém 27 itens que se referem a uma auto-avaliação de reações fisiológicas, comportamentais e afetivo-emocionais. As autoras concluem que crianças vítimas de queimadura parecem ser mais depressivas do que as crianças do grupo "normal", porém não em nível estatisticamente significante. É ressaltada a importância de levantar estados depressivos em crianças vítimas de queimaduras como medida de prevenção de problemas mais graves de comportamento.

De acordo com esses estudos nacionais, observa-se que autores brasileiros têm se esforçado em colaborar na adequação de instrumentos estrangeiros para uso na população brasileira, assim como para acentuar sobre a importância deles (Pereira, 2002).

Os autores acima descritos salientaram ainda que os fatores regionais, econômicos e culturais são relevantes no estudo da depressão na infância; as características psicopatológicas de crianças brasileiras são diferentes daquelas das de outros países. Desse modo, há necessidade urgente de conhecer mais sobre o construto depressão infantil nas crianças brasileiras. Percebe-se a importância que tem sido dada ao desenvolvimento e utilização de escalas de auto-avaliação para estudos epidemiológicos, pesquisas científicas e promoção de saúde mental da população mais jovem. A construção de mais instrumentos viabiliza um estudo da depressão infantil em amostras de crianças de diversos Estados brasileiros e a promoção de estudos psicométricos dos instrumentos a partir da comparação entre eles (Pereira, 2002).

\section{MÉTODO}

\section{Sujeitos}

A presente pesquisa contou com cinco grupos de amostras de sujeitos. Nos três primeiros grupos foi realizada a análise teórica dos itens (análise semântica e análise de construto dos itens) e nos outros dois grupos, a análise quantitativa (análise fatorial e precisão).

O Grupo 1 contou com 12 crianças de uma escola pública municipal da região do Vale do Paraíba - SP, com idades variando de seis a onze anos, sendo $50 \%$ do sexo feminino e $50 \%$ do sexo masculino. As 12 crianças foram divididas em quatro grupos, denominados de Grupo 1A, Grupo 1B, Grupo 1C e Grupo 1D.

O Grupo 2 foi constituído de quatro crianças com idades de seis a nove anos, sendo $75 \%$ do sexo feminino e $25 \%$ do sexo masculino, de uma escola particular da região do Vale do Paraíba-SP.

O Grupo 3 foi composto de sete profissionais que trabalham com depressão infantil, sendo quatro psicólogos clínicos da área da Psicologia Comportamental e três psiquiatras. Este grupo respondeu à ficha de análise de juízes.

O Grupo 4 foi formado por 214 crianças de uma escola pública municipal da região do Vale do Paraíba - SP, com idades variando de seis a 12 anos, sendo $60 \%$ do sexo feminino e $40 \%$ do sexo masculino. O Grupo 5 foi formado por 148 crianças de duas escolas particulares da região do Vale do Paraíba - SP, com idades variando de seis a 12 anos, sendo $47 \%$ do sexo feminino e $53 \%$ do sexo masculino.

\section{Material}

Durante a realização da pesquisa, a "Escala de Avaliação de Depressão para Crianças" passou por quatro versões.

\section{Primeira Versão}

Amaral e Barbosa (1990) desenvolveram a "Escala de Auto-Avaliação de Depressão para Crianças" por meio de levantamento, na literatura, dos instrumentos internacionais de avaliação do comportamento depressivo freqüentemente utilizados. Os instrumentos investigados foram: 
os de Hamilton, 1960; Beck \& col., 1961; Zung \& Durham, 1965; Ponznanski \& col., 1970; Knesevich \& col., 1977; Ponznanski \& col., 1979; Carlson \& Cantwell, 1980; Cytryn \& col., 1980; Lefkowitz \& Tesiny, 1980; e, do Brasil, o de Gongora (1984) (apud Amaral e Barbosa, 1990). Os instrumentos foram traduzidos e analisados por três juízes, de acordo com o DSM-III (1978), a fim de verificar os itens mais pertinentes para o diagnóstico da depressão infantil. Desse modo, a escala foi composta de 27 itens, que englobaram reações afetivo-emocionais, fisiológicas e comportamentais na depressão infantil. As respostas aos itens são dadas com base em três intervalos da escala Likert: Sim, Às vezes e Não. A forma de pontuação da escala foi estabelecida do seguinte modo: Sim = dois pontos; Às Vezes = um ponto; Não = zero ponto.

\section{Segunda Versão}

Para a realização da presente pesquisa, inicialmente foram efetuadas algumas modificações na "Escala de Avaliação de Depressão para Crianças" pela própria autora do instrumento. As alterações foram: mudança do título da escala de Auto-Avaliação para Avaliação, pois no caso de crianças de seis anos ou que ainda não sabem ler, a escala é aplicada por um profissional, e não auto-aplicada; reformulação de alguns itens; e a inserção da Resposta Cognitiva. Os itens reformulados foram: Item 9. "Eu sempre tenho medo de alguma coisa" para "Eu sinto medo sempre". Item 10. "Eu sempre sinto que vou ser castigado" para "Eu sinto que sempre vou ser castigado". Item 12. "Eu tenho chorado ou tenho tido sempre vontade de chorar" para "Eu choro sempre ou tenho sempre vontade de chorar". Item 13. "Eu prefiro brincar sempre sozinho" para "Eu prefiro brincar sozinho". Item 14. "Eu me acho um(a) menino(a) mau (má)" para "Eu sinto que sou um(a) menino(a) mau (má)". Item 15. "Eu não tento novamente quando eu perco" para "Eu desisto quando erro alguma coisa". Item 17. "Eu sempre acho que não sei fazer as coisas" para "Eu faço tudo errado". Item 18. "Eu me preocupo muito com as coisas" para "Eu me preocupo muito". Item 19. "Eu acho que os outros não gostam de mim" para "Eu acho que os outros gostam de mim". Item 21. "Eu sempre sinto que estou fazendo alguma coisa errada" para "Eu sinto que sempre estou fazendo coisas erradas". Item 22. "Eu não gosto de mim" para "Eu gosto de mim". Item 24. "Eu perdi meu interesse pelas pessoas e não ligo para ninguém" para "Eu gosto das pessoas e de estar com elas". Item 26. "Eu tenho dificuldade para dormir" para "Eu demoro para dormir". Assim, a "Escala de Avaliação de Depressão para Crianças" ficou composta de 27 itens, divididos em quatro dimensões de respostas da depressão em crianças: resposta afetivo-emocional; resposta cognitiva; resposta fisiológico-autonômica; e resposta Comportamento-observável.

\section{Terceira Versão}

Antes de ser realizada a análise teórica dos itens, os advérbios de freqüência foram retirados dos itens, pois na instrução foi adicionada a expressão nas duas últimas semanas. Também foi adicionado um exemplo retirado do RCDS (Reynolds Child Depression Scale): "Eu sinto vontade de ver televisão". Além disso, foram realizadas as seguintes alterações: o item 12 foi alterado de "Eu choro ou tenho vontade de chorar" para "Eu sinto vontade de chorar"; o item 14 foi alterado de "Eu sinto que sou um(a) menino(a) mau (má)" para "Eu sinto que sou mau (má)"; o item 15, de "Eu desisto quando erro alguma coisa", para "Eu desisto quando erro"; o item 16, "Eu durmo na sala de aula" foi eliminado, por ser considerado pouco consistente com a fundamentação teórica. Foi substituído pelo item "Eu sinto que meus pais não gostam de mim", retirado do RCDS (Reynolds Child Depression Scale); o item 23 foi reformulado: de "Eu acho que sou culpado quando alguma coisa acontece de errado na minha casa", para "Eu acho que sou culpado quando alguma coisa acontece de errado"; o item 24 foi reformulado de "Eu gosto das pessoas e de estar com elas" para "Eu gosto das pessoas"; o item 25 "Eu me acho feio" foi eliminado, por ser considerado pouco consistente 
com a fundamentação teórica. Foi substituído pelo item "Eu me sinto amado", retirado do RCDS (Reynolds Child Depression Scale). Além disso, foram incluídos mais três itens na escala, retirados do RCDS (Reynolds Child Depression Scale): item 28 - "Eu me sinto sozinho"; item 29 - "Eu me sinto importante"; item 30 - "Eu sinto que ninguém se preocupa comigo".

O acréscimo de itens teve como finalidade facilitar a análise estatística dos itens e tornar mais abrangente a amostra das respostas indicativas do construto depressão infantil, contribuindo também com o estudo da precisão. A "Escala de Avaliação de Depressão para Crianças" ficou, então, composta por 30 itens divididos nas quatro dimensões de respostas da depressão em crianças descritas na versão anterior.

\section{Quarta Versão}

A quarta versão foi realizada após toda a análise teórica dos itens; desse modo mantiveram-se, a instrução e o exemplo da terceira versão. O item 26 "Eu demoro para dormir" foi complementado com: “....... quando já estou deitado"; o item 27 "Eu não sinto vontade de comer" foi reformulado para: "Eu não tenho fome"; e o item 28 "Eu me sinto sozinho" foi reformulado para: "Eu me sinto abandonado". 0 item 23 foi excluído: "Eu acho que sou culpado quando alguma coisa acontece de errado". As respostas aos itens foram dadas com base em três intervalos da escala Likert: Sim, Às vezes e Não. A forma de pontuação da escala foi estabelecida do seguinte modo: $\operatorname{Sim}=$ três pontos; Às vezes $=$ dois pontos; Não $=$ um ponto. Os itens 19, 22, 23, 24 e 28 foram pontuados inversamente: $\mathrm{Sim}=$ um ponto; Às vezes $=$ dois pontos; Não = três pontos.

Com a quarta versão, a "Escala de Avaliação de Depressão para Crianças" ficou pronta para aplicação numa amostra maior de sujeitos, visando posteriormente à realização da análise fatorial exploratória e precisão do instrumento.

\section{PROCEDIMENTO}

\section{Análise Semântica dos Itens}

Para a primeira fase de coleta de dados foram escolhidas uma escola pública municipal e uma escola particular, ambas da região do Vale do Paraíba - SP, nas quais a pesquisadora explicou o objetivo de sua pesquisa e obteve o consentimento das mesmas para a sua realização. Para realização da análise semântica dos itens e compreensão das instruções e do modo de assinalar as respostas, solicitou-se a autorização do responsável pela criança para participação nessa fase de coleta de dados.

A análise semântica foi realizada no Grupo 1. A técnica utilizada para análise de compreensão dos itens foi dividir o Grupo 1 em pequenos grupos nos quais os itens foram checados numa situação de brainstorming. Por meio desta técnica, consiste em que os sujeitos expressam todas as suas idéias a respeito do item. Oitem, quando compreendido corretamente, era mantido. Caso contrário, o item era então reformulado ou descartado. Com a finalidade de verificar a instrução e o modo de assinalar as respostas, foi pedido aos sujeitos que respondessem à escala.

Os itens da "Escala de Avaliação de Depressão para Crianças", incluindo os já reformulados, foram conferidos pelo mesmo método num grupo de sujeitos de uma escola particular - Grupo 2 - com o objetivo de que não perdessem sua validade aparente.

\section{Análise dos Juízes}

Os profissionais receberam duas listas. A primeira delas continha as definições, descritas pela pesquisadora, de cada um dos fatores contidos na escala; a segunda lista, em forma de tabela, continha os itens da escala descritos à direita e os fatores relacionados acima. No lado esquerdo da tabela os profissionais marcaram com um $X$ a resposta que acharam que o item estava representando. 
O critério de pertinência do item foi atribuído após uma concordância de pelo menos $80 \%$ dos os juízes sobre a representatividade do item em determinado fator.

\section{Análise Quantitativa dos Itens}

Foi escolhida pela pesquisadora uma escola pública municipal e duas escolas particulares, todas da região do Vale do Paraíba - SP. Duas das escolas já haviam participado da primeira fase de coleta de dados; então não houve necessidade de nova explicação sobre a pesquisa, já que a pesquisadora havia exposto todo o processo de coleta de dados anteriormente. $\mathrm{Na}$ outra escola particular, escolhida pela facilidade de acesso, explicou-se o objetivo da pesquisa e obteve-se o consentimento. Nessa segunda fase também solicitou-se a autorização do responsável de cada criança.

Para as aplicações no Grupo 4 e no Grupo 5 foi utilizada a quarta versão da "Escala de Avaliação de Depressão para Crianças", ou seja, conforme os resultados obtidos na análise qualitativa. As aplicações da escala ocorreram durante o período autorizado. As crianças tiveram tempo livre para responder (tempo médio $=20$ minutos). Foi realizado um breve rapport com as crianças, a fim de garantir tranqüilidade, explicar o objetivo deste estudo e o respeito aos princípios éticos da pesquisa científica aos sujeitos.

\section{RESULTADOS}

\section{Análise Semântica dos Itens}

No processo da análise teórica, somente um item, que avalia a culpa na depressão, precisou ser descartado, devido à sua incompreensão em todos os grupos. O item excluído foi: Item 23 - "Eu acho que sou culpado quando alguma coisa acontece de errado".

Os itens reformulados foram: item 26 - "Eu demoro para dormir"; item 27 - "Eu não sinto vontade de comer" e item 28 - "Eu me sinto sozinho". Estes três itens não foram compreen- didos adequadamente em nenhum dos quatro grupos. O item 26 - "Eu demoro para dormir" - foi complementado com: “... quando já estou deitado". O item 27 - "Eu não sinto vontade de comer" - foi reformulado para: "Eu não tenho fome". O item 28 - "Eu me sinto sozinho" - foi reformulado para: "Eu me sinto abandonado".

Com relação à compreensão da instrução do instrumento e do exemplo, a pesquisadora concluiu que as crianças do Grupo 1 não apresentaram dificuldades nem divergências de entendimento. Na apresentação das respostas e forma de assinalá-las, os sujeitos não demonstraram dúvidas ou hesitação.

Os itens, incluindo os já reformulados pela análise anterior, foram checados pelo mesmo método, no Grupo 2, com o objetivo de não perderem sua validade aparente. Todos os itens foram compreendidos adequadamente pelas crianças.

\section{Análise dos Juízes}

A segunda etapa, de análise teórica dos itens da "Escala de Avaliação de Depressão para Crianças", foi realizada pelos profissionais do Grupo 3. Dois juízes sugeriram unir os fatores resposta afetivo-emocional e resposta cognitiva, pois a maioria dos itens encontra-se saturada por esses dois fatores. Não houve itens descartados, pois considerou-se que a maioria deles apresentava saturações em dois fatores e, neste caso, a discordância dos juízes foi considerada como concordância.

\section{Análise Quantitativa dos Itens}

A análise quantitativa da "Escala de Avaliação de Depressão para Crianças" foi realizada com utilização do SPSS - Statistical Package for Social Sciences (Versão 7.5 for Windows).

O primeiro passo foi medir o $\mathrm{KMO}$ - Kaiser-Meyer-Olkin Measure of Sampling Adequacy. O KMO encontrado foi de 0,804 , representando uma adequação boa dos dados à análise fatorial. 


\section{Análise Fatorial Exploratória}

Aplicando-se o método dos componentes principais aos itens da "Escala de Avaliação de
Depressão para Crianças", foi possível verificar os autovalores e suas respectivas porcentagens de explicação.

Tabela 1. Explicação dos Fatores de uma Análise Fatorial obtida a partir de uma Análise de Componentes Principais.

\begin{tabular}{|c|c|c|c|}
\hline FATOR & AUTOVALOR & EXPLICAÇÃO (\%) & EXPLICAÇÃO ACUMULADA (\%) \\
\hline 1 & 4,51 & 15,658 & 15,658 \\
\hline 2 & 2,205 & 7,602 & 23,261 \\
\hline 3 & 1,500 & 5,173 & 28,434 \\
\hline 4 & 1,429 & 4,928 & 33,361 \\
\hline 5 & 1,257 & 4,334 & 37,695 \\
\hline 6 & 1,178 & 4,063 & 41,758 \\
\hline 7 & 1,088 & 3,753 & 45,512 \\
\hline 8 & 1,55 & 3,638 & 49,150 \\
\hline 9 & 1,047 & 3,610 & 52,760 \\
\hline 10 & 0,969 & 3,340 & 56,100 \\
\hline 11 & 0,958 & 3,303 & 59,402 \\
\hline 12 & 0,915 & 3,154 & 62,557 \\
\hline 13 & 0,896 & 3,088 & 65,645 \\
\hline 14 & 0,830 & 2,860 & 68,506 \\
\hline 15 & 0,790 & 2,725 & 71,230 \\
\hline 16 & 0,749 & 2,582 & 73,812 \\
\hline 17 & 0,733 & 2,529 & 76,341 \\
\hline 18 & 0,698 & 2,406 & 78,747 \\
\hline 19 & 0,685 & 2,363 & 81,110 \\
\hline 20 & 0,656 & 2,263 & 83,373 \\
\hline 21 & 0,651 & 2,246 & 85,619 \\
\hline 22 & 0,610 & 2,104 & 87,723 \\
\hline 23 & 0,564 & 1,944 & 89,667 \\
\hline 24 & 0,559 & 1,927 & 91,594 \\
\hline 25 & 0,538 & 1,855 & 93,449 \\
\hline 26 & 0,533 & 1,837 & 95,289 \\
\hline 27 & 0,477 & 1,643 & 96,929 \\
\hline 28 & 0,451 & 1,554 & 98,484 \\
\hline 29 & 0,440 & 1,516 & 100,000 \\
\hline
\end{tabular}


Nota-se, na Tabela 1, que o primeiro fator sozinho explica 15,65\% da variabilidade total dos dados. Os dois primeiros fatores explicam, em conjunto, $23,26 \%$ da variabilidade total e assim, até que se atinja $100 \%$ de explicação ao se considerar todos os 29 fatores. O instrumento

Tabela 2. Comunalidades Referentes a uma Solução com Quatro Fatores.

\begin{tabular}{|c|c|}
\hline ITEM & COMUNALIDADE \\
\hline 1 & 0,256 \\
\hline 2 & 0,305 \\
\hline 3 & 0,301 \\
\hline 4 & 0,410 \\
\hline 5 & 0,273 \\
\hline 6 & 0,338 \\
\hline 7 & 0,291 \\
\hline 8 & 0,293 \\
\hline 9 & 0,356 \\
\hline 10 & 0,390 \\
\hline 11 & 0,461 \\
\hline 12 & 0,539 \\
\hline 13 & 0,201 \\
\hline 14 & 0,417 \\
\hline 15 & 0,231 \\
\hline 16 & 0,389 \\
\hline 17 & 0,340 \\
\hline 18 & 0,365 \\
\hline 19 & 0,372 \\
\hline 20 & 0,294 \\
\hline 21 & 0,287 \\
\hline 22 & 0,419 \\
\hline 23 & 0,344 \\
\hline 24 & 0,495 \\
\hline 25 & 0,201 \\
\hline 26 & 0,074 \\
\hline 27 & 0,354 \\
\hline 28 & 0,340 \\
\hline 29 & 0,336 \\
\hline
\end{tabular}

demonstrou ser fatorialmente mais complexo do que se esperava, já que apresentou nove fatores com autovalores acima de 1,00. Observa-se que os quatro primeiros fatores explicam, conjuntamente, $33,36 \%$ da variabilidade total dos dados; e apresentam autovalores acima de 1,4.

A Tabela 2 mostra as comunalidades da solução com quatro fatores. Os dados sugerem um ajuste regular, já que apenas $33,36 \%$ da variabilidade total está sendo explicada. Segundo as comunalidades, o item mais bem explicado pelos fatores é o item 12 , com $54 \%$, e o pior é o item 26 , com $7 \%$, destacado em negrito.

A análise fatorial adotada foi a de componentes principais com rotação Varimax com extração de quatro fatores, cujo agrupamento de itens é observado na Tabela 3, que apresenta o peso (carga) de cada um dos itens em cada fator. Foram consideradas como significativas para um fator as cargas fatoriais acima de 0,40. $\mathrm{Na}$ Tabela 3, esses valores encontram-se em negrito.

Desse modo, conclui-se que: os itens 1 , 10, 11, 14, 17, 20, 21 e 27 predominam na definição do Fator 1; os itens 4, 6, 9, 12 e 18 predominam no Fator 2; os itens 2, 3, 5, 7, 8 e 29 predominam no Fator 3 ; e os itens 16, 19, 22, 24 e 28 predominam no Fator 4.

Avaliando o que há de comum em cada um dos quatro fatores, verifica-se que no Fator 1 os itens agrupados são os mais representativos na escala, responsáveis por $15,65 \%$ da variância total, e referem-se a uma resposta de afeto disfórico. No Fator 2 verifica-se resposta afetivo-emocional com conteúdo de ansiedade, e os itens deste fator são responsáveis por 7,6\% da variância total. Os itens do Fator 3 apresentam a dimensão de resposta fisiológico-autonômica, e explicam $5,1 \%$ da variância total. No Fator 4 observa-se a dimensão de resposta cognitiva com conteúdo de auto-estima, e os itens explicam $4,9 \%$ da variância total. Todas as dimensões de respostas são vinculadas ao construto depressão infantil medido pelo instrumento. Os itens 13 - "Eu prefiro brincar sozinho"; 15 - "Eu desisto quando erro"; 23 - "Eu gosto das pessoas"; 
25 - "Eu demoro para dormir quando já estou deitado" e 26-"Eu não tenho fome" apresentaram cargas fatoriais não significativas e foram descartados do instrumento.

Tabela 3. Cargas Fatoriais para Solução com Quatro Fatores com Rotação Varimax

\begin{tabular}{|c|c|c|c|c|c|}
\hline ITENS DA ESCALA & & FATOR 1 & FATOR 2 & FATOR 3 & FATOR 4 \\
\hline 1. Eu me sinto irritado. & & 0,423 & 0,157 & 0,216 & 0,075 \\
\hline 10. Eu sinto que vou ser castigado. & & 0,511 & 0,290 & 0,150 & $-0,150$ \\
\hline 11. Eu tenho vontade de morrer. & & 0,669 & $-0,110$ & 0,034 & 0,048 \\
\hline 14. Eu sinto que sou mau. & & 0,634 & 0,122 & 0,037 & 0,028 \\
\hline 17. Eu faço tudo errado. & & 0,552 & 0,039 & 0,138 & 0,123 \\
\hline 20. Eu me sinto aborrecido. & & 0,485 & 0,051 & 0,229 & 0,057 \\
\hline 21. Eu sinto que estou fazendo coisas erradas & & 0,474 & 0,222 & $-0,113$ & 0,018 \\
\hline 27. Eu me sinto abandonado & & 0,502 & 0,163 & 0,099 & 0,256 \\
\hline 4. Eu me sinto triste. & & 0,349 & 0,510 & 0,121 & 0,117 \\
\hline 6. Eu estou preocupado com a minha saúde. & & 0,033 & 0,520 & 0,202 & $-0,161$ \\
\hline 9. Eu sinto medo. & & 0,221 & 0,506 & 0,164 & 0,156 \\
\hline 12. Eu sinto vontade de chorar. & & 0,189 & 0,702 & 0,095 & 0,042 \\
\hline 18. Eu me preocupo muito. & & 0,155 & 0,550 & 0,195 & 0,033 \\
\hline 2. Eu me sinto cansado. & & 0,020 & 0,188 & 0,515 & 0,062 \\
\hline 3. Eu tenho vontade de ficar deitado. & & 0,047 & 0,018 & 0,545 & 0,043 \\
\hline 5. Eu tenho sentido dor de cabeça. & & 0,184 & 0,170 & 0,453 & 0,068 \\
\hline 7. Eu sinto fraqueza no meu corpo. & & 0,255 & 0,213 & 0,418 & 0,072 \\
\hline 8. Eu tenho desmaiado. & & 0,245 & $-0,210$ & 0,419 & $-0,116$ \\
\hline 15. Eu desisto quando erro. & & 0,244 & 0,165 & 0,379 & 0,018 \\
\hline 25. Eu demoro para dormir quando já estou deitado. & & 0,209 & $-0,271$ & 0,283 & 0,063 \\
\hline 26. Eu não tenho fome. & & 0,083 & 0,089 & 0,234 & 0,065 \\
\hline 29. Eu sinto que ninguém se preocupa comigo. & & 0,352 & 0,063 & 0,445 & 0,100 \\
\hline 13. Eu prefiro brincar sozinho. & & 0,012 & 0,060 & 0,291 & 0,336 \\
\hline 16. Eu sinto que meus pais não gostam de mim. & 19. & 0,219 & 0,127 & 0,402 & 0,404 \\
\hline Eu acho que os outros gostam de mim. & & 0,086 & 0,084 & 0,076 & 0,593 \\
\hline 22. Eu gosto de mim. & & 0,383 & $-0,167$ & $-0,193$ & 0,456 \\
\hline 23. Eu gosto das pessoas. & & 0,155 & $-0,423$ & 0,135 & 0,350 \\
\hline 24. Eu me sinto amado. & & $-0,144$ & 0,034 & 0,087 & 0,683 \\
\hline 28. Eu me sinto importante. & & 0,018 & 0,109 & $-0,185$ & 0,542 \\
\hline
\end{tabular}




\section{Análise do Poder Discriminativo e da Consistência Interna}

Na Tabela 4, observa-se o desvio-padrão e a correlação corrigida entre item e total de cada item - correlação de Pearson ( $r$ ).

De acordo com a análise desses dados, foi possível verificar o quanto os itens, numa escala
Likert, são capazes de discriminar os sujeitos. Os itens demonstraram bons índices de discriminação em relação aos seus fatores.

A precisão, realizada por meio da análise do Coeficiente Alfa (a) de Cronbach, também pode ser observada na Tabela 4 . O valor do alfa nos oito itens do primeiro fator da escala, resposta afeto disfórico, foi de 0,70 ; no segundo fator,

Tabela 4. Média, Desvio-Padrão dos Itens, Correlação Corrigida de Pearson (r) Item-Total e Precisão (Coeficiente Alfa de Cronbach).

\begin{tabular}{|c|c|c|c|c|c|}
\hline FATOR & TEM & MÉDIA & DESVIO-PADRÃO & CORRELAÇÃO & $\alpha$ DECRONBACH \\
\hline \multirow{8}{*}{1} & 1 & 1,84 & 0,68 & 0,33 & \multirow[t]{8}{*}{0,70} \\
\hline & 10 & 1,63 & 0,75 & 0,42 & \\
\hline & 11 & 1,24 & 0,52 & 0,41 & \\
\hline & 14 & 1,37 & 0,61 & 0,45 & \\
\hline & 17 & 1,58 & 0,65 & 0,43 & \\
\hline & 20 & 1,64 & 0,71 & 0,37 & \\
\hline & 21 & 1,78 & 0,74 & 0,36 & \\
\hline & 27 & 1,42 & 0,66 & 0,40 & \\
\hline \multirow{5}{*}{2} & 4 & 1,77 & 0,72 & 0,40 & \multirow{5}{*}{0,65} \\
\hline & 6 & 2,19 & 0,87 & 0,35 & \\
\hline & 9 & 1,74 & 0,74 & 0,35 & \\
\hline & 12 & 1,87 & 0,71 & 0,50 & \\
\hline & 18 & 2,03 & 0,81 & 0,43 & \\
\hline \multirow{6}{*}{3} & 2 & 2,10 & 0,69 & 0,32 & \multirow{6}{*}{0,56} \\
\hline & 3 & 2,07 & 0,79 & 0,20 & \\
\hline & 5 & 1,85 & 0,80 & 0,37 & \\
\hline & 7 & 1,53 & 0,68 & 0,32 & \\
\hline & 8 & 1,16 & 0,48 & 0,26 & \\
\hline & 29 & 1,76 & 0,81 & 0,36 & \\
\hline \multirow{5}{*}{4} & 16 & 1,59 & 0,80 & 0,20 & \multirow{5}{*}{0,49} \\
\hline & 19 & 1,48 & 0,69 & 0,32 & \\
\hline & 22 & 1,20 & 0,52 & 0,28 & \\
\hline & 24 & 1,52 & 0,75 & 0,33 & \\
\hline & 28 & 1,65 & 0,74 & 0,26 & \\
\hline
\end{tabular}


resposta afetivo-emocional com conteúdo de ansiedade, foi de 0,65 ; no terceiro fator, resposta fisiológico-autonômica foi de 0,56 ; e no quarto fator, resposta cognitiva com conteúdo de autoestima, foi de 0,50.

\section{DISCUSSÃO}

O processo de validação de um instrumento psicométrico é primordial, sendo coerente com Anastasi e Urbina (2000), que citam que a validade de um teste responde pelo grau em que ele mede aquilo que se propõe a medir.

Como já foi descrito na metodologia, a escala original passou por diversas etapas até chegar a uma quarta versão, que constituiu o instrumento piloto. Segundo (Oakland, 1999), as revisões e eliminações nos itens, assim como o acréscimo deles, são necessárias no processo de validação.

Outra preocupação da autora do instrumento foi a inclusão da resposta cognitiva, da primeira para a segunda versão do instrumento, ampliando as dimensões envolvidas na depressão infantil. Conforme Miller (1998), os sintomas típicos da depressão infantil envolvem quatro classes principais de distúrbios: 1) pensamento; 2) emoções; 3) comportamento e 4) processo fisiológico.

Na primeira fase do processo de validação realizou-se o conteúdo semântico dos itens e a análise de juízes, processo fundamental num estudo de validação (Pasquali, 1999). Os itens, as instruções, o exemplo e o modo de assinalar as respostas foram colocados à prova de compreensão de sua população-alvo.

$\mathrm{Na}$ análise de juízes, o instrumento foi avaliado por profissionais capacitados para 0 atendimento às crianças deprimidas. A consulta aos profissionais é adequada para julgamento dos itens (Adánez, 1999; Oakland, 1999). Assim, a pertinência dos itens ao construto depressão infantil e a inserção desses nos quatro fatores foram reafirmadas pelos profissionais. Desse modo, os requisitos da análise teórica dos itens foram cumpridos, e o instrumento piloto ficou constituído de 29 itens de respostas ligadas ao construto depressão infantil. Seguindo o processo de validação do instrumento, a segunda fase direcionou-se ao refinamento empírico do instrumento.

A validação do instrumento foi obtida por meio do método de validação de construto que, segundo Cunha (1994), visa tornar o instrumento uma medida operacional do construto, ou seja, a depressão infantil. Desse modo, o método da análise fatorial exploratória foi aplicado ao instrumento. Este é freqüentemente utilizado quando o objetivo primeiro do instrumento é medir adequadamente um construto psicológico (Adánez, 1999).

A análise fatorial exploratória, que trabalha com o agrupamento de variâncias, detectou consistência em quatro fatores agrupados, que explicam $33,36 \%$ da variabilidade total dos dados, com autovalores acima de 1,4. A porcentagem de explicação da variabilidade total está próxima de valores encontrados na literatura. A pesquisadora optou por trabalhar com quatro fatores. Os fatores foram interpretados a partir daquilo que os itens apresentavam em comum.

No Fator 1 predominou a resposta de afeto disfórico. A descrição de sintomas nos itens refere-se a sentimentos e pensamentos que a criança possui em relação a si mesma, na depressão infantil. No afeto disfórico, a criança pensa a partir de sua própria perspectiva, envolvendo culpa (item 10 - "Eu sinto que vou ser castigado"; item 21 - "Eu sinto que estou fazendo coisas erradas"), autocrítica (item 14 - "Eu sinto que sou mau"; item 17 - "Eu faço tudo errado"). Em relação aos sentimentos observa-se o humor deprimido (item 1 - "Eu me sinto irritado"; item 20 - "Eu me sinto aborrecido"; item 27 - "Eu me sinto abandonado") e a falta de interesse (item 11 - "Eu tenho vontade de morrer").

O Fator 2 foi caracterizado pela resposta afetivo-emocional com conteúdo de ansiedade da depressão infantil; os itens envolvem processos psicológicos subjetivos e ansiedade: sentimentos de tristeza, angústia e preocupação 
(item 4 - "Eu me sinto triste"; item 6 - "Eu estou preocupado com a minha saúde"; item 9 - "Eu sinto medo"; item 6 - "Eu sinto vontade de chorar"; item 18 - "Eu me preocupo muito").

No Fator 3, os itens referem-se à resposta fisiológico-autonômica, e envolvem uma reação interna do organismo controlada pelo sistema nervoso autônomo. Fadiga, falta de energia, dores físicas e desconforto estão presentes na depressão infantil (item 2-"Eu me sinto cansado"; item 3 - "Eu tenho vontade de ficar deitado"; item 5-"Eu tenho sentido dor de cabeça"; item 7-"Eu sinto fraqueza no meu corpo"; item 8 - "Eu tenho desmaiado"; item 29 - "Eu sinto que ninguém se preocupa comigo").

O Fator 4 revela a resposta cognitiva com conteúdo de auto-estima. Refere-se ao pensamento que a criança tem de si mesma em relação a sentimentos de valor próprio (item 22 - "Eu gosto de mim"; item 24 - "Eu me sinto amado"; item 28 - "Eu me sinto importante") e a sentimentos de valor que outros possuem em relação a ela (item 16 - "Eu sinto que meus pais não gostam de mim"; item 19 - "Eu acho que os outros gostam de mim").

Os fatores da escala demonstraram ter boa precisão. Adánez (1999) afirma que, seja qual for o formato do item, os valores iguais ou inferiores a zero indicam uma consistência inadequada, pois a confiabilidade dos itens não contribui para a homogeneidade do teste nem a diminui. Quanto maiores forem os desvios típicos dos itens e as correlações dos itens com o teste, maior será o coeficiente alfa de Cronbach, e o valor deste coeficiente pode variar de zero a um.

A metodologia de medição da depressão é encontrada na literatura em forma de escala de medida de auto-relato, em que o sujeito se expressa de acordo com a graduação das respostas, viabilizando a medida da presença e severidade de sintomas da depressão, considerando-se as dimensões clinicamente relevantes desse construto. Contudo, uma preocupação desses instrumentos é garantir uma boa representação do construto que pretende medir. Uma boa validação e a precisão dessas medidas são imprescindíveis. Além disso, o cuidado a ser tomado é evitar que essas medidas não forneçam um diagnóstico específico de desordem depressiva. Portanto, tais medidas possuem suas limitações, como qualquer instrumento de medição de comportamentos, não devendo ser utilizada de forma isolada.

\section{CONCLUSÃO}

O presente estudo procurou cumprir os requisitos básicos de um processo de validação de instrumentos psicométricos. A "Escala de Avaliação de Depressão para Crianças" ficou composta de 24 itens, que avaliam a sintomatologia da depressão em quatro fatores: afeto disfórico, afetivo-emocional com conteúdo de ansiedade, fisiológico-autonômica e cognitiva com conteúdo de auto-estima.

Nesse primeiro estudo de validação, a escala não se comprometeu a avaliar todas as dimensões envolvidas no construto depressão infantil. Contudo, a análise fatorial exploratória conseguiu identificar fatores com um grau razoável de interpretação.

Pode-se dizer que a "Escala de Avaliação de Depressão para Crianças" mostrou ser uma medida válida e com precisão adequada. Entretanto, novos estudos deverão ser realizados, principalmente novas pesquisas de validação junto à população clínica, para que sua eficácia possa ser melhorada.

A escala visa auxiliar profissionais capacitados que estão constantemente em contato com crianças, e envolvidos em pesquisas científicas que englobam a depressão infantil. Esta escala é uma primeira tentativa de auxiliar o preenchimento da lacuna de instrumentos psicométricos que meçam a depressão infantil no contexto cultural brasileiro, contribuindo para a literatura científica nacional e promovendo o conhecimento da depressão infantil, ainda carente de estudo em nossa população.

\section{REFERÊNCIAS BIBLIOGRÁFICAS}

ADÁNEZ, G. P. (1999). Procedimentos de Construcción y Analisis de Tests Psicome- 
tricos. In Wechsler, S. M. \& Guzzo, R. S. L., Avaliação Psicológica: Perspectiva Internacional (pp.57-100). São Paulo: Casa do Psicólogo.

AMARAL, V. L. A. R. \& Barbosa, M. K. (1990). Crianças Vítimas de Queimaduras: Um Estudo Sobre Depressão. Estudos de Psicologia, 7 (1), 31-59.

ANASTASI, A., \& Urbina, S. (2000). Natureza e Uso dos Testes Psicológicos. In Anastasi, A. \& Urbina, S., Testagem Psicológica (pp.17 a 36). (7 ${ }^{\mathrm{a}}$ ed.). (M. A. V. Veronese, trad.). Porto Alegre: Artes Médicas Sul.

ANDRIOLA, W. B. \& Cavalcante, L. R. (1999). Avaliação da Depressão Infantil em Aluno da Pré-Escola. Psicologia: Reflexão e Crítica, 12 (2), 419- 428.

ASSOCIAÇÃO AMERICANA DE PSIQUIATRIA (2000). Manual Diagnóstico e Estatístico de Transtornos Mentais (4 ${ }^{\mathrm{a}}$ ed.). (D. Batista, trad.). Porto Alegre: Artes Médicas Sul. (original de 1994).

ASSUMPÇÃO Jr., F. B. (2000). Diagnóstico e Quadro Clínico da Depressão na Infância e na Adolescência. In Lafer, B., Almeida, O. P. , Fráguas, R. \& Miguel, E. C., Depressão no Ciclo da Vida (pp.37-44). Porto Alegre: Artes Médicas Sul.

BAPTISTA, C. A. \& Golfeto, J. H. (2000). Prevalência de Depressão em Escolares de sete a 14 anos. http://www.hcnet.usp.brlipq/ revista/27(5)/artigos/art 253.htm. 27/05/2000.

BIRMAHER, B., Ryan, N. D., Williamson, D. E., Brent, D. A. \& Kaufman, J. (1996). Childhood and Adolescent Depression: A Review of the Past 10 Years. Part II. Journal of the American Academy of Child \& Adolescent Psychiatry. 35 (12), 1575-1583.

BROWN, Anne. Mood Disorders in Children and Adolescents. http://www.mhsource.com./ narsad/childmood.html. 07/11/2000.

CALIL, M. H. \& Pires, M. L. N. (2000). Aspectos Gerais das Escalas de Avaliação de Depressão. In Gorestein, C., Andrade, L.H.S.G. \& Zuardi, A. W. (eds.). Escalas de Avaliação Clínica em Psicologia e
Psicofarmacologia (pp. 65-69). São Paulo: Lemos-Editorial.

CUNHA, S. E. (1994). A Noção de Validade de Testes Psicológicos. Rio de Janeiro: CEPA.

Gill, K. S., Coffey, B. J. \& Park, K. S. (2000). Transtorno Bipolar na Infância e na Adolescência. In Lafer, B., Almeida, O. P., Fráguas, R. \& Miguel, E. C., Depressão no Ciclo da Vida (pp.110-114). Porto Alegre: Artes Médicas Sul.

GOUVEIA, V. V., Barbosa, G. A., Almeida, H. J. F. \& Gaião, A. A. (1995). Inventário de Depressão Infantil - CDI: Estudo de Adaptação com Escolares de João Pessoa. Jornal Brasileiro de Psiquiatria, 44 (7), 345-349.

HODGES, K. K., Siegel, L. J., Mullins, L. \& Griffin, N. (1983). Factor Analysis of the Children's Depression Inventory. Psychological Reports. 53, 759-763.

MCCLELLAN, J. \& Werry, J. S. (1997). Practice Parameters for the Assessment and Treatment of Children and Adolescents With Bipolar Disorder. Journal of the American Academy of Child \& Adolescent Psychiatry. 36 (10), 157S-176S.

MESQUITA, P. B. \& Gilliam, W. S. (1994). Differential Diagnosis of Childhood Depression: Using Comorbidity and Symptom Overlap to Generate Multiple Hypotheses. Child Psychiatry and Human Development.24 (3), 157-172.

MILLER, J. A. (1998). The Childhood Depression Sourcebook. Los Angeles: NTC/ Contemporary Publishing Group.

MORENO, A. R. \& Moreno, D. H (2000). Escalas de Avaliação para Depressão de Hamilton (HAM-D) e Montgomery- Åsberg (MADRS). In Gorestein, C., Andrade, L.H.S.G. \& Zuardi, A. W. (eds.). Escalas de Avaliação Clínica em Psicologia e Psicofarmacologia (pp. 71-87). São Paulo: Lemos- Editorial.

NOTTELMANN, E. D. \& Jensen, P. S. (1995). Bipolar Affective Disorder in Children and Adolescents. Journal of the American Academy of Child \& Adolescent Psychiatry. 34 (6), 705-708. 